\title{
An uncommon case of horizontal Gaze Palsy with scoliosis and associated brain-stem anomaly (HGPPS)
}

\author{
Dr. Rajendra Nath Gogoi ${ }^{1}$, Dr. Amit S. Nene ${ }^{1}$, Dr. Anoop Mishra ${ }^{1}$ \\ ${ }^{I}$ (Department of Ophthalmology, Assam Medical College \& Hospital, Dibrugarh, Assam, India)
}

\begin{abstract}
HGPPS is a rare congenital disorder resulting from cranial nuclear maldevelopment and characterized by absence of conjugate horizontal eye movements, preservation of vertical gaze \& convergence, progressive scoliosis developing in childhood and hypoplasia of dorsomedial brainstem structures associated with sagittal cleft of pons and medulla. We present a 19 years old male, with restriction of eye movements, reduced visual acuity \& had clinical and imaging findings of HGPPS. The patient revealed bilateral horizontal gaze palsy with normal vertical eye movements and normal convergence. Best corrected visual acuity was 6/24 in right eye \& 6/36 in left eye.PA view X-ray spine show thoraco-lumbar scoliotic deformity. MRI revealed split pons sign associated with hypoplasia of pons \& medulla. Hypoplasia of the dorsomedial brainstem structures leads to defect of the abducens nucleus and MLF which leads to horizontal gaze palsy whereas scoliosis could be due to chronic muscle tone abnormalities resulting from primary brainstem anomaly.
\end{abstract}

Keywords: congenital, horizontal gaze palsy, scoliosis, split pons sign.

\section{Introduction}

Horizontal gaze palsy with progressive scoliosis (HGPPS) is a known clinical entity, as a part of congenital cranial dysinnervation disorder syndrome (CCDDs).[1]The term CCDDs was derived in 2002 at a European Neuromuscular Centre (ENMC) international workshop for a group of congenital neuromuscular diseases reflecting the belief that these disorders resulted from developmental errors in innervation. The main CCDDs currently recognised and subdivided, are as shown in TABLE1.

Table 1 Classification of CCDDs

\begin{tabular}{|l|l|}
\hline $\begin{array}{l}\text { Predominantly vertical disorder of ocular motility } \\
\text { C Congenital fibrosis of the extraocular muscles } \\
(\text { CFEOM) }\end{array}$ & $\begin{array}{l}\text { Predominantly horizontal disorder of ocular motility } \\
\text { - Duane syndrome (DS) } \\
\text { - DS + radial ray (DRRS) } \\
\text { - Horizontal gaze palsy with progressive scoliosis (HGPPS) }\end{array}$ \\
\hline $\begin{array}{l}\text { Disorder of facial motility } \\
\text { - Congenital facial palsy }\end{array}$ & $\begin{array}{l}\text { Disorder of facial motility and ocular abduction deficit } \\
\text { - Möbius syndrome }\end{array}$ \\
\hline
\end{tabular}

Horizontal gaze palsy with progressive scoliosis (HGPPS; On-Line Mendelian Inheritance in Man accession number 607313) is a rare autosomal recessive disorder characterized by congenital absence of conjugate horizontal eye movements, preservation of vertical gaze and convergence, and progressive scoliosis developing in childhood and adolescence.[2]

\section{Case report}

A 19 -year-old male, was referred to our hospital for evaluation of restriction of eye movements and reduced visual acuity. He was born at term, to healthy nonconsanguineous parents after an uneventful pregnancy. He was noted to have complete absence of horizontal eye movements since the neonatal period (Fig.1), whereas vertical eye movements and convergence were preserved (Fig. 2). He compensated for his deficit by turning his head in the desired direction, thereby obtaining regular binocular vision. Neurologic examination was otherwise normal. Thoracolumbar scoliosis was noted at age 4 years by visual inspection; corset treatment was attempted from age 2 to 10 years but failed to halt progression.

Visual acuity was $6 / 60$ in each eye (uncorrected) and 6/24 in right eye and 6/36 in left eye after best possible optical correction. Horizontal movements could not be elicited with the Doll's head manoeuvre. Horizontal saccades and pursuit movements were absent. No evidence of facial weakness was noted in neurological examination. 

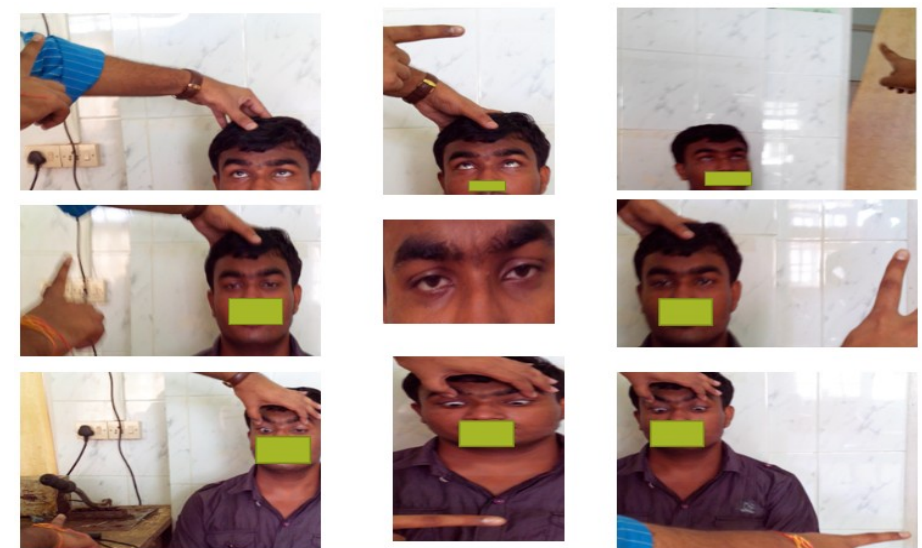

figure 1: showing complete absence of horizontal eye movements

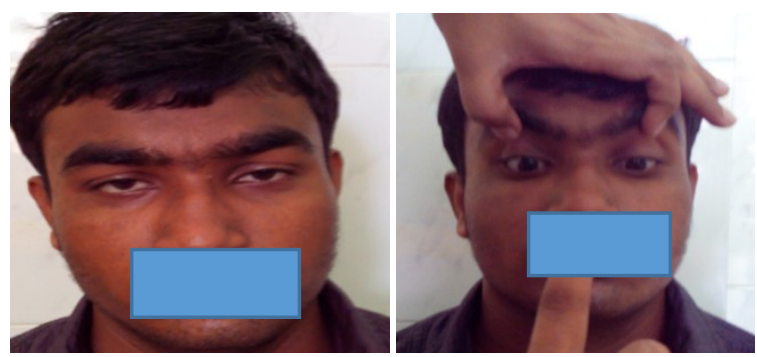

figure 2: showing normal convergence

MR imaging revealed T1 hypo and T2 hyperintense deep midline extending ventrally from floor of 4th ventricle across the Pons giving "SPLIT PONS SIGN" and extending inferiorly upto superior medulla oblongata. Hypoplasia of pons and medulla were noted. There was absence of facial colliculi with tenting appearance of floor of the fourth ventricle. Rectangular shaped medulla oblongata was noted with deep anterior median sulcus. Atrophic changes of anterior protuberances of medulla oblongata were noted with more prominence of olivary protuberances(Fig. 3).
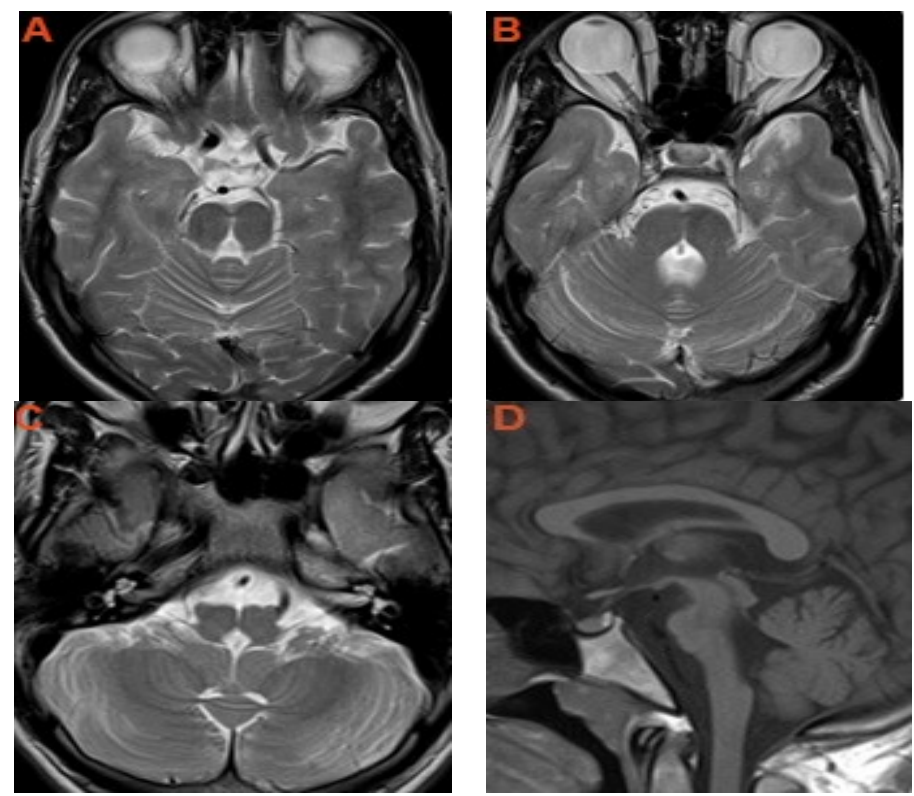

figure 3: Axial T2WI (A, B) images demonstrate tenting of fourth ventricle, absence of the facial colliculi impression, and sagittal clefting of Pons, giving a "split Pons sign". At a more caudal level, axial T2WI (C) demonstrates a rectangular and butterfly appearance of the medulla oblongata. There is relative prominence of the inferior olivary nuclei. Sagittal T1WI (D) demonstrates atrophy of Pons and medulla. 
Plain radiograph of spine in AP projection showed thoraco-lumbar scoliotic deformity with convexity towards left side with apex at D10 vertebral level and had Cobb Lippman's angle of $23^{\circ}$ (Fig. 4).

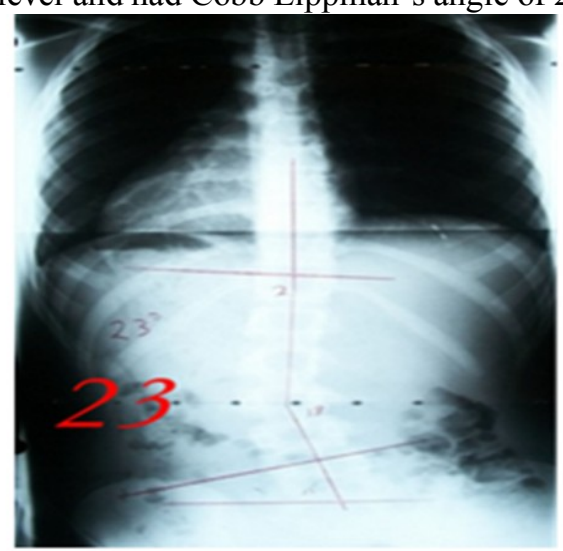

figure 4: X-ray spine AP view showing Cobb angle 0 f $23^{\circ}$ with apex at D10

\section{Discussion}

The patient presented with left thoracic scoliosis, with apex at D10 vertebrae and ophthalmic examination showed complete horizontal gaze palsy. The first descriptions of associated horizontal gaze palsy and scoliosis date back to 40 years. In 1974, Crisfield observed four Chinese siblings with severe scoliosis and progressive external ophthalmoplegia, and Dretakis and Kondoyannis reported five other cases from two nonconsanguineous families.[3][4]In 1975, Sharpe et al considered the association of paralysis of horizontal gaze, pendular nystagmus, and progressive scoliosis to constitute a distinctive heredofamiliar syndrome.[5]In reviewing the literature more than 20 years later, Thomsen et al found 11 articles reporting 39 patients with the combination of progressive scoliosis and familial congenital gaze palsy.[6]In 2002, Jen et al described six patients from two nonconsanguineous families and mapped the disease locus to a $30-\mathrm{cM}$ interval on chromosome 11q23-25.[2]

Bi-allelic mutations in the Roundabout homolog of Drosophila 3 (ROBO3) gene cause horizontal gaze palsy with progressive scoliosis (HGPPS; OMIM 607313), a rare autosomal recessive disorder with oculomotor and general disturbances in innervation.[7][8]

The oculomotor signs of HGPPS comprise congenital absence of horizontal gaze under the conditions of conjugate gaze at smooth pursuit, saccades, and vestibulo-ocular or optokinetic responses. In the majority of cases, adduction is preserved under the condition of convergence.Nystagmus presents in many patients and is mostly horizontal and pendular, with low amplitude.[9][10]Sporadically, nystagmus is accompanied by slight involuntary head movements. Several patients display asynchronous blinking. Visual fields, pupil function, accommodation, and anterior and posterior segments of the eye are unremarkable. Visual acuity is reported not to be grossly impaired .[11]

The $\mathrm{ROBO} 3$ protein plays a critical role in ensuring that motor and sensory nerve pathways cross over in the brainstem. In people with HGPPS, these pathways do not cross over, but stay on the same side of the body. Researchers believe that this miswiring in the brainstem is the underlying cause of the eye movement abnormalities associated with the disorder. The cause of progressive scoliosis in HGPPS is unclear.Such dysfunction could involve the proprioceptive inputs, mediated by the posterior column pathways of spinal cord and medial lemniscus, the postural equilibrium and labyrinthine function mediated by the vestibular nuclei, and the interplay of visual and vestibular reflexes mediated by the superior colliculus and MLF. Significantly, experimental kyphoscoliosis has been induced in rats by selective brain-stem damage involving the gracile nucleus, the lateral vestibular nucleus, and the superior colliculus.[12]

\section{Conclusion}

Despite the extensive neuroanatomical derangements present in HGPPS, patients have preserved motor and sensory function and coordination. Even though some studies have attempted to clarify the mechanisms that lead to the clinical observations characteristic of HGPPS, there is still a great requirement for research aimed at determining the molecular mechanisms involved in the stimulation of pathway decussation by $\mathrm{ROBO} 3$ products. A clinical misdiagnosis is highly unlikely in this situation since the combination of progressive scoliosis with full horizontal gaze palsy is, so far, exclusive to HGPPS. 


\section{References}

[1] Gutowski NJ, Bosley T, Engle E. The Congenital Cranial Dysinnervation Disorders (CCDDs). Neuromuscular Disorders 2003;13:573-8.

[2] Jen, J., Coulin, C. J., Bosley, T. M., Salih, M. A. M., Sabatti, C., Nelson, S. F., Baloh, R. W. Familial horizontal gaze palsy with progressive scoliosis maps to chromosome 11q23-25. Neurology 59: 432-435, 2002.

[3] Crisfield RJ. Scoliosis with progressive external ophthalmoplegia in four siblings. J Bone Joint Surg 1974;56B:484-489.

[4] Dretakis EK, Kondoyannis PN. Congenital scoliosis associated with encephalopathy in five children of two families. J Bone Joint Surg 1974;56A:1747-1750.

[5] Sharpe JA, Silversides JL, Blair RD. Familial paralysis of horizontal gaze: associated with pendular nystagmus, progressive scoliosis, and facial contraction with myokymia. Neurology 1975;25:1035-1040 .

[6] Thomsen M, Steffen H, Sabo D, Niethard FU. Juvenile progressive scoliosis and congenital horizontal gaze palsy. J Pediatr Orthop B 1996;5:185-189.

[7] Jen JC, Chan WM, Bosley TM, Wan J et al. Mutations in a human ROBO gene disrupt hindbrain axon pathway crossing and morphogenesis. Science. 2004; 304:1509-13.

[8] Chan WM, Traboulsi EI, Arthur B, Friedman N, Andrews C, Engle EC. Horizontal gaze palsy with progressive scoliosis can result from compound heterozygous mutations in ROBO3. J Med Genet. 2006; 43:e11.

[9] Amouri R, Nehdi H, Bouhlal Y, Kefi M, Larnaout A, Hentati F. Allelic ROBO3 heterogeneity in Tunisian patients with horizontal gaze palsy with progressive scoliosis. J Mol Neurosci. 2009; 39:337-41.

[10] Haller S, Wetzel SG, Lutschg J. Functional MRI, DTI and neurophysiology in horizontal gaze palsy with progressive scoliosis.Neuroradiology. 2008; 50:453-9.

[11] Abu-Amero KK, al Dhalaan H, al Zayed Z, Hellani A, Bosley TM. Five new consanguineous families with horizontal gaze palsy and progressive scoliosis and novel ROBO3 mutations. J Neurol Sci. 2009; 276:22-6.

[12] Barrios C, Arrotegui JI. Experimental kyphoscoliosis induced in rats by selective brain stem damage. Int Orthop 1992;16:146-151. 